\title{
MECANISMOS DE IDENTIFICACIÓN DE PALABRAS EN NIÑOS DISLÉXICOS EN ESPAÑOL: ¿EXISTEN SUBTIPOS?
}

\section{MECHANISMS OF WORD IDENTIFICATION IN DYSLEXIC CHILDREN IN SPANISH DYSLEXIC CHILDREN: DO SUBTYPES EXIST?}

\author{
Marisol Carrillo \\ Universidad de Murcia, España \\ Jesús Alegría \\ Université Libre de Bruxelles, Bélgica
}

\begin{abstract}
Resumen: Utilizando un test de lectura de frases para evaluar el nivel de eficiencia lectora de escolares de $3^{\circ}$ a $6^{\circ}$ de educación primaria, fueron seleccionados 60 niños con más de dos años de retraso específico en lectura (disléxicos) y 65 normolectores (control edad). El objetivo era establecer la existencia de un déficit del mecanismo de lectura fonológico (evaluado con lectura de pseudopalabras) y, consecuentemente, del mecanismo léxico-ortográfico (evaluado con escritura de palabras inconsistentes). Se utilizó el análisis de regresión para poner en evidencia subtipos de disléxicos caracterizados por puntajes desequilibrados entre las dos medidas. Los resultados globales muestran déficits importantes a nivel fonológico y ortográfico. La clasificación en subtipos señala una mayoría de disléxicos "armónicos" y "de superficie" sin aparecer claramente el subtipo "fonológico". La proporción de armónicos aumenta con el nivel escolar y alcanza el $90 \%$ del grupo de disléxicos en $6^{\circ}$ año. Los resultados son interpretados en el marco del modelo de autoenseñanza. La ausencia de disléxicos fonológicos es interpretada considerando que estos casos aparecen típicamente en sistemas ortográficos opacos en los cuales el mecanismo de ensamblado fonológico es poco fiable, lo que induce a la memorización de imágenes ortográficas de las palabras.
\end{abstract}

Palabras clave: retraso especifico en lectura, dislexia de desarrollo, procesamiento fonológico, subtipos de dislexia, modelo de autoenseñanza.

\begin{abstract}
The reading efficiency level of primary education children at 3rd to 6th grade was assessed using a phrase reading test. Two groups were selected: dyslexics $(n=60)$, which presented more than 2 years of specific reading retardation, and a control group $(n=65)$ of age-equivalent normal readers. The aim of the study was to establish the existence of a deficit in the phonological processing mechanism (evaluated with a pseudo-word reading task) and, consequently, in the lexical-orthographic mechanism (evaluated with an inconsistent word spelling task). Dyslexic subtypes were detected by using the regression method, characterised by the fact that the score in one of the tasks was not correctly predicted by the score in the other. The global results indicate a substantial deficit in both phonological and orthographic tasks. Classification into subgroups showed that most dyslexics belonged to either "harmonic" or "surface" categories. No children could be clearly characterized as "phonological" dyslexics. The proportion of harmonic dyslexics increased with the school grade and reached $90 \%$ in 6 th grade. The results are discussed in the framework of the self-teaching model. The absence of phonological dyslexics was explained by considering that these cases appear consistently in opaque orthographic systems, in which phonological coding is not reliable, and which would lead readers to memorize orthographic representations of words.
\end{abstract}

Keywords: specific reading retardation, developmental dyslexia, phonological processing, dyslexia subtypes, self-teaching model.

Este artículo se sustenta en una investigación parcialmente financiada dentro del Proyecto : Mejora del diagnóstico de la dislexia en español: fundamentos para un estudio longitudinal. Referencia SEJ 2007 - 67661/PSIC. Ministerio de Ciencia y Tecnología. Ha recibido el apoyo de la Fundación Séneca-Agencia de Ciencia y Tecnología- de la Consejería de Educación y Cultura de la C.A. de Murcia.

Correspondencia: Marisol Carrillo. Departamento de Psicología Evolutiva y de la Educación. Facultad de Psicologia. Universidad de Murcia .Correo electrónico: mscarri@um.es. 


\section{INTRODUCCIÓN}

\section{La dislexia: problema fonológico}

El concepto de dislexia ha ido evolucionando en el curso de las últimas décadas y aparece hoy claramente como un problema de base neurológica que afecta el procesamiento de la información fonológica a diferentes niveles (Morton \& Frith, 1995; Ramus, 2006; Ramus, Rosen, Dakin, Day, Castellote, White \& Frith, 2003). Aunque las consecuencias de este problema sobre el desarrollo de la lengua oral pueden ser leves (Manis, McBride-Chang, Seidenberg, Keating, Doi et al., 1997), no ocurre igual con el aprendizaje de la lengua escrita, sobre el que causa una grave perturbación.

Nos situamos, por tanto, en un marco teórico en el que las dificultades de aprendizaje de la lectura están causalmente ligadas a un déficit fonológico y en el que se considera que el procesamiento fonológico incluye diferentes niveles o dimensiones, algunas ligadas específicamente a la lectura y otras no (véase Alegría \& Mousty, 2004).

Se ha demostrado en numerosos estudios que los disléxicos tienen deficiencias en diversas tareas que no implican leer, pero cuyo denominador común es la utilización de representaciones fonológicas de las palabras. Por ejemplo, los disléxicos son más lentos que los normolectores nombrando imágenes (Bowers \& Wolf, 1993; Denckla \& Cutting, 1999; Wolf \& Bowers, 2000) y también son peores en tareas de fluidez verbal tales como dar nombres de ejemplares de una categoría semántica (ej. animales) o bajo criterio fonético (ej. palabras que empiezan con /s/). También se ha demostrado que los disléxicos tienen resultados inferiores a los normolectores en tareas de memoria a corto plazo (Brady, 1991). La memorización, del mismo modo que las tareas en que el sujeto tiene que nombrar explícitamente objetos, implica la activación de representaciones fonológicas de los ítems a memorizar (véase Carrillo, en prensa; Carrillo \& Alegría, 2009; Maillart, Van Reybroeck, 2005).

La dimensión de la fonología que la relaciona específicamente con la lectura proviene del código alfabético. En efecto, la lengua escrita representa la lengua oral a nivel fonológico: las palabras escritas son secuencias de letras a las que corresponden secuencias de fonemas. La identificación de palabras escritas es la actividad de base de la lectura, condición sine qua non de ésta, ya que es inconcebible leer frases o textos más amplios sin ser capaz de identificar, al menos, una buena parte de las palabras que forman la frase. Aprender a identificar palabras escritas eficientemente plantea problemas a los disléxicos porque implica actividades mentales de carácter fonológico (Stanovich, 1996, 1998).

El proceso de base en la adquisición de mecanismos de identificación de palabras escritas es el llamado ensamblaje fonológico, que consiste en atribuir secuencias fonológicas a secuencias ortográficas y ensamblarlas en una entidad que corresponde eventualmente a una palabra conocida. En el transcurso del aprendizaje, esta actividad se hace cada vez mas automática en el lector normal, pero no así en el disléxico, para quien el ensamblaje fonológico no llega a automatizarse y sigue siendo lento y susceptible de errores.

La identificación de palabras por ensamblaje, tiene una función dinámica en el desarrollo del sistema en su conjunto; ya que contribuye progresivamente a la constitución de un léxico ortográfico que almacena representaciones de las palabras escritas, permitiendo identificarlas por medio de un nuevo mecanismo de acceso directo.

El modelo de autoenseñanza propuesto por Share (1995, 1999) articula entre sí a estos dos procesos: el ensamblaje que permite identificar palabras nuevas o poco frecuentes para las que el lector no posee una representación ortográfica, y el acceso directo que permite la identificación de las palabras que se hayan leído con frecuencia y que se desarrolla gracias a la actividad de ensamblaje.

Una hipótesis central de este trabajo es que el mecanismo de ensamblaje es deficiente en los disléxicos y está en el origen de sus dificultades de aprendizaje de la lectura.

\section{Tipos de dislexia}

El modelo de autoenseñanza bosquejado aquí supone una causa única (o principal) de la dislexia, a saber, una deficiencia fonológica que afecta el mecanismo de ensamblaje. Como el acceso directo proviene del ensamblaje, las diferencias individuales en este último tendrían 
que explicar las diferencias en el primero y esto tendría que traducirse en un síndrome único explicativo de la dislexia. Así, el aprendizaje de la lectura dependería en última instancia del funcionamiento del mecanismo fonológico. Pero contrariamente a este análisis, son clásicos algunos estudios de casos, realizados en los años 80 , que mostraron diferentes perfiles de dislexia de desarrollo (Campbell \& Butterworth, 1985; Temple \& Marshall, 1983) sugiriendo que la dislexia evolutiva, a semejanza de las dislexias adquiridas, no es un síndrome homogéneo sino que puede presentarse en forma de síndromes diferentes: la dislexia llamada de superficie, caracterizada por deficiencias graves en el mecanismo de acceso directo (pobreza del léxico ortográfico) y la dislexia fonológica en la que el problema afecta al mecanismo grafo-fonológico de ensamblado.

Esta tipología se inspira en la patología de las dislexias adquiridas en la que aparecen casos de lectores adultos normales quienes, como consecuencia de un accidente neurológico localizado, pierden la capacidad de ensamblaje (disléxicos fonológicos), o bien la capacidad de acceso directo (disléxicos de superficie).

Los primeros son incapaces de leer pseudopalabras, pero leen correctamente palabras con ortografía irregular o excepcional que exigen la participación del léxico ortográfico (Beauvois \& Derouesné, 1979).

Los segundos, por el contrario, han conservado las capacidades de ensamblaje, gracias a lo cual pueden leer correctamente pseudopalabras pero no las palabras irregulares o excepcionales (Coltheart, Materson, Byng, Prior \& Ridodoch, 1983). Por ejemplo, la palabra irregular (en inglés) "island" /ailand/ en la que no se pronuncia la "s", será leída como si fuera regular, /island/ .

El problema de ensamblaje en los disléxicos fonológicos hace que en los casos extremos (disléxicos profundos) se produzcan errores de lectura llamados "paralexias semánticas". Así un disléxico profundo ante la palabra aislada "history" puede leer "ancient" (Marshall \& Newcombe, 1973).

Estos casos de dislexia adquirida son un argumento importante en cuanto a la existencia de dos mecanismos separables de identificación de palabras (Coltheart, 1981), ya que un accidente cerebral puede afectar gravemente uno de ellos y dejar el otro intacto.
La cuestión planteada por ciertos autores es la de saber si estos síndromes se pueden extender a la dislexia de desarrollo o solo constituyen los casos extremos de una distribución no categorial (Morais, 1994). En respuesta a esta cuestión, en el curso de los años 90 comienzan a aparecer en lengua inglesa trabajos sobre amplios grupos de disléxicos, que utilizan una metodología denominada de regresión para valorar el grado de disociación en el desarrollo de los dos mecanismos de identificación de palabras (Castles \& Coltheart, 1993; Manis, Seidenberg, Doi, McBride-Chang \& Petersen, 1996; Stanovich, Siegel, Gottardo, Chiappe, y Sidhu, 1997). El procedimiento toma como base la relación que se considera normal en el desarrollo de ambos mecanismos, para lo cual se establece la regresión entre la capacidad de ensamblaje (evaluada con una tarea de lectura de pseudopalabras) y la capacidad de acceso directo (evaluada con una tarea de lectura de palabras irregulares) en un grupo de normolectores (bien de la misma edad cronológica, bien de la misma edad lectora que la de los disléxicos en estudio).

A continuación se establecen los límites de confianza de la recta de regresión que engloban al $95 \%$ de la población y, finalmente, se sitúan los resultados de los disléxicos en este esquema. Los casos cuya puntuación en lectura de palabras irregulares se sitúe por debajo del límite previsto por la regresión establecida con los lectores normales, serán considerados disléxicos de superficie. Del mismo modo, pero estableciendo la regresión de la lectura de pseudopalabras en función del nivel en palabras, se detectan los disléxicos fonológicos.

Los casos cuyas puntuaciones en las dos tareas sobrepasen los límites se consideran casos "severos", mientras que los casos con ambas puntuaciones dentro de los límites se denominan "armónicos" o "moderados".

La aplicación de esta técnica ha permitido establecer en inglés la presencia tanto de disléxicos fonológicos como de disléxicos de superficie: $55 \%$ y $30 \%$, respectivamente, en el estudio de Castles \& Coltheart (1993), 33\% y $29 \%$ en Mannis et al. (1996), y $25 \%$ y $22 \%$ en Stanovich et al. (1997).

En francés, sin embargo, el estudio de Genard, Mousty, Content, Alegría, Leybaert \& Morais (1998) sobre un grupo de 75 disléxicos mostró un $56 \%$ de superficiales pero solamente 
un $4 \%$ de fonológicos. A ese bajo porcentaje de disléxicos fonológicos hay que agregar el hecho que sus habilidades de lectura de palabras irregulares, dependientes del mecanismo ortográfico de acceso directo, se situaban apenas por encima del nivel previsto a partir de sus habilidades fonológicas.

La diferencia de la incidencia del síndrome fonológico en francés y en inglés podría ser el resultado del carácter particularmente opaco de la ortografía del inglés.

Esto podría llevar al aprendiz lector anglófono a memorizar gran número de palabras a causa de la escasa fiabilidad del código alfabético en esta lengua.

Por el contrario, en lenguas transparentes como el castellano, incluso los disléxicos pueden lograr un dominio suficiente del código para leer sin error la mayoría de palabras y pseudopalabras (Calvo, 1999; Davies, Cuetos \& González-Seijas, 2007). Además, al menos para leer, el mecanismo ortográfico no resulta necesario al no existir palabras irregulares, lo que puede tener consecuencias en el desarrollo de mecanismos de identificación de palabras.

\section{Dislexia y transparencia fonológica}

Las lenguas se distinguen entre ellas por la mayor o menor transparencia de la relación entre su forma oral y escrita.

En los sistemas ortográficos transparentes como el del español, el alemán y otros, la relación grafema - fonema (lectura) y fonema - grafema (escritura) es relativamente simple y consistente.

En otros sistemas la traducción es inconsistente: un fonema puede ser traducido ortográficamente de varias maneras y viceversa. Se habla en estos casos de sistemas opacos y el inglés es uno de ellos.

El francés ocupa un lugar intermedio, es opaco en escritura pero relativamente transparente en lectura, aunque más complejo que el español y el alemán. La complejidad del código alfabético determina en buena parte la mayor o menor rapidez de aprendizaje de la lectura (Seymour, Aro \& Erskine, 2003).

En las lenguas cuyo sistema ortográfico es transparente, la adquisición de la lectura y la escritura es considerablemente más rápida que en las opacas. Así lo muestran, entre otros, los estudios comparativos entre alemán e inglés (Wimmer \& Goswami, 1994), entre español y portugués (Defior, Martos \& Cary, 2002); entre inglés, español y francés (Goswami, Gombert \& Fraca de Barbera, 1998) y entre francés y español (Alegría, Marín, Carrillo \& Mousty, 2003). La simplicidad del código facilita el aprendizaje de la lectura a través de la facilidad de utilización del mecanismo de ensamblaje. La pregunta que cabe hacerse es: ¿cómo va a manifestarse la dislexia en lenguas con ortografía transparente?

La comparación del alemán con el inglés muestra que los disléxicos germanófonos de $2^{\circ}$ y $4^{\circ}$ curso cometen considerablemente menos errores leyendo palabras y pseudo-palabras que los disléxicos anglófonos del mismo nivel escolar (Landerl, Wimmer \& Frith, 1997). Sin embargo los disléxicos germanófonos presentan un déficit importante y persistente de velocidad de lectura (véase también Wimmer, 1993, 1996). Así mismo, en el estudio de Calvo (1999), los disléxicos hispanohablantes de $4^{\circ}, 5^{\circ}$ y $6^{\circ}$ curso mostraron elevados niveles de exactitud en lectura de palabras y pseudopalabras ( $95 \%$ y $81 \%$ de aciertos respectivamente) pero dedicaron casi el doble de tiempo que los normolectores para leerlas. A pesar de las altas puntuaciones en exactitud de los lectores con dificultades, las diferencias resultaron significativas cuando se les comparó con el grupo "control edad" y con el grupo "control lector", lo cual indica que también en una lengua transparente la dislexia está asociada a un déficit fonológico.

Por su parte, en la tarea destinada a evaluar el mecanismo ortográfico (elegir entre dos homófonos el que corresponde a la palabra escrita correctamente; p.ej huevo - huebo), las puntuaciones fueron similares a las del grupo control lector, lo que indica que los disléxicos presentan un retraso en el desarrollo del léxico ortográfico en consonancia con el bajo nivel de eficiencia lectora. Resultados similares fueron encontrados en los estudios de Martínez (1995), Jiménez y Ramírez (2002) y Cuadro y Marín (2007).

Estos resultados muestran que los disléxicos no están al abrigo de dificultades de lectura cuando tienen que aprender en un sistema transparente.

\section{OBJETIVOS DEL ESTUDIO}

En este estudio vamos a examinar los mecanismos de lectura de palabras y pseudopalabras en escolares disléxicos y normolectores 
de escuela primaria.

El objetivo es establecer la existencia de un déficit en el mecanismo de ensamblaje y, consecuentemente, en el acceso léxico-ortográfico. La velocidad y la exactitud de la lectura de palabras y pseudopalabras serán examinadas a fin de establecer sus valores respectivos en tanto que manifestación de problemas de lectura en una lengua como en español. Utilizaremos finalmente el método de regresión a fin de detectar la presencia de tipos diferentes de disléxicos.

\section{MÉTODO}

\section{Participantes}

En una población de 757 escolares, de los cursos $3^{\circ}$ a $6^{\circ}$ de Educación Primaria de siete colegios públicos de la Región de Murcia (España) con nivel socioeconómico medio y medio-bajo, se identificaron los casos de grave retraso lector a partir de los resultados en el test TECLE de Eficacia Lectora (Marín \& Carrillo, 1997). Fueron excluidos 61 escolares que presentaban algún déficit sensorial, problema cognitivo, conductual o afectivo grave, o bien problemas notables en el dominio de la lengua oral (inmigrantes de origen latinoamericano y magrebí, fundamentalmente). A continuación se aplicó un primer criterio de selección en cada grupo de clase (aula), incluyéndose en la muestra los casos con puntuaciones inferiores al valor de la media menos 1 s.d. (desviación típica). De esta forma se considera como referencia del retraso el nivel del aula, controlándose así diferencias socio-culturales y educativas que pudieran diferenciar a las aulas entre sí.
A continuación, y con el mismo fin, se aplicó un segundo criterio (media menos 1 s.d.) tomando como referencia el nivel de cada curso con independencia del aula y el centro escolar, excluyéndose así los casos con bajo rendimiento respecto al aula pero no con respecto al resto de alumnos evaluados del mismo curso. De esta forma la muestra quedó compuesta por 60 escolares que cumplen los criterios de exclusión de la dislexia.

Además, fue seleccionada una muestra de 65 normolectores (grupo control edad) procedentes de las mismas aulas en las que fueron identificados los lectores retrasados, y una segunda muestra de 15 normolectores más jóvenes, de $2^{\circ}$ curso, con nivel lector similar al del grupo de disléxicos (grupo control lector). En la tabla 1 se muestra la distribución de los sujetos por nivel lector y curso escolar y se detallan las puntuaciones correspondientes en Eficacia Lectora de cada uno de los grupos.

\section{Materiales y procedimiento}

La selección de las muestras de disléxicos y normolectores se basó, tal como acabamos de señalar, en los resultados del Test TECLE de Eficacia lectora (Marín \& Carrillo, 1997) aplicado colectivamente en cada una de las aulas. Para la determinación del nivel de dominio del mecanismo fonológico de lectura se utilizó una prueba experimental de lectura en voz alta de palabras y pseudopalabras de aplicación individual, y para la evaluación del mecanismo ortográfico se utilizó una prueba de escritura al dictado de palabras conteniendo grafonemas inconsistentes, de aplicación colectiva (véase, Carrillo en prensa, Carrillo \& Alegría, 2009).

Tabla 1. Número de escolares (N) por Curso escolar y Nivel lector. Media en Eficacia Lectora $\left(\mathrm{n}^{\mathrm{o}}\right.$ de aciertos en el Test TECLE) y edad (meses) de normolectores y disléxicos en cada curso

\begin{tabular}{|c|c|c|c|c|c|c|c|c|c|c|}
\hline \multirow[b]{2}{*}{ Curso } & \multicolumn{2}{|r|}{$2^{\circ}$} & \multicolumn{2}{|r|}{$3^{\circ}$} & \multicolumn{2}{|r|}{$4^{\circ}$} & \multicolumn{2}{|r|}{$5^{\circ}$} & \multicolumn{2}{|r|}{$6^{\circ}$} \\
\hline & $\begin{array}{l}\mathrm{N} \\
\text { edad }\end{array}$ & $\begin{array}{l}\text { Eficiencia } \\
\text { Lectora }\end{array}$ & $\begin{array}{l}\mathrm{N} \\
\text { edad }\end{array}$ & $\begin{array}{l}\text { Eficiencia } \\
\text { Lectora }\end{array}$ & $\begin{array}{l}\mathrm{N} \\
\text { edad }\end{array}$ & $\begin{array}{l}\text { Eficiencia } \\
\text { Lectora }\end{array}$ & $\begin{array}{l}\mathrm{N} \\
\text { edad }\end{array}$ & $\begin{array}{l}\text { Eficiencia } \\
\text { Lectora }\end{array}$ & $\begin{array}{l}\mathrm{N} \\
\text { edad }\end{array}$ & $\begin{array}{l}\text { Eficiencia } \\
\text { Lectora }\end{array}$ \\
\hline $\begin{array}{l}\text { Normo- } \\
\text { lectores }\end{array}$ & $\begin{array}{l}15 \\
\text { (92) }\end{array}$ & 19,3 & $\begin{array}{l}22 \\
\text { (104) }\end{array}$ & 23,8 & $\begin{array}{l}10 \\
(118)\end{array}$ & 26 & $\begin{array}{l}18 \\
\text { (130) }\end{array}$ & 35,3 & $\begin{array}{l}15 \\
(146)\end{array}$ & 37,4 \\
\hline Disléxicos & & & $\begin{array}{l}29 \\
(106)\end{array}$ & 11,5 & $\begin{array}{l}7 \\
\text { (119) }\end{array}$ & 13,4 & $\begin{array}{l}14 \\
(135)\end{array}$ & 15,6 & $\begin{array}{l}10 \\
(147)\end{array}$ & 21,6 \\
\hline
\end{tabular}


a) Prueba de Eficacia Lectora (Test TECLE): esta prueba, diseñada para obtener un indicador global del nivel lector, combina los dos elementos que definen la eficacia lectora: comprensión y rapidez. La puntuación depende tanto de la comprensión de las frases que se incluyen como de la rapidez con la que se conteste a cada una de ellas. Requiere, por tanto, exactitud y velocidad en la identificación de las palabras escritas, así como conocimientos lexicales, morfológicos y sintácticos, pero no presenta una fuerte carga de memoria ni de habilidades de comprensión lingüística general.

Estímulos y procedimiento: el test consta de 64 frases a las que les falta la última palabra y debajo de cada una de ellas se presentan, en posición variable, cuatro opciones de respuesta (palabra adecuada, palabra de ortografía similar pero no adecuada semántica o sintácticamente, pseudopalabra similar gráficamente a la opción correcta y pseudopalabra similar fonológicamente a dicha opción). Las frases, que varían en complejidad morfosintáctica y familiaridad léxica, se presentan en un cuadernillo ordenadas de menor a mayor longitud. Las instrucciones, que fueron dadas verbalmente a cada grupo de aula, incluyen la realización previa de dos frases de ensayo e indican que se dispone de 5 minutos para completar el mayor número de frases que se pueda. La puntuación es el número de frases completadas correctamente en el tiempo estipulado.

b) Lectura de palabras y pseudopalabras: la lectura en voz alta de pseudopalabras permite evaluar el funcionamiento del mecanismo de recodificación fonológica. Además, la comparación del nivel alcanzado en lectura de pseudopalabras con el alcanzado en lectura de palabras de igual complejidad grafofonológica permite valorar el mayor o menor uso del mecanismo léxico-ortográfico.

Estímulos y procedimiento: La prueba de lectura de palabras se compone de 36 palabras familiares (estructuras ortográficas representativas del léxico): 12 palabras bisilábicas (de 4 a 6 grafemas), 12 trisilábicas (de 6 a 10 grafemas) y 12 tetrasilábicas (de 8 a 12 grafemas). Por su parte, los 36 ítems de la prueba de lectura de pseudopalabras están formados recombinando las sílabas de las palabras de la lista anterior, dentro de cada grupo de longitud y respetando la posición de las sílabas, resultando por tanto, 12 bisilábicas, 12 trisilábicas y 12 tetrasilábicas. El orden de presentación tanto en la lista de palabras como en la de pseudopalabras alterna ítems de longitudes diferentes.

Estas pruebas se administran de forma individual. Al sujeto se le indica que debe leer cada lista sin detenerse hasta el final y procurando no equivocarse. Se comienza con la lectura de 4 ítems de ejemplo, tras lo cual se pone el cronómetro en marcha y al finalizar cada prueba se anotan los segundos empleados. Las respuestas son grabadas en calidad digital para su posterior análisis. Además de la exactitud $\left(n^{\circ}\right.$ de ítems leídos correctamente y sin errores leves de rectificación, repetición o silabeo marcado) también el tiempo empleado en la lectura de cada lista se consideró como variable.

c) Prueba de conocimiento ortográfico: para evaluar el desarrollo del mecanismo léxico-ortográfico, y en sustitución de la lectura de palabras irregulares (no existentes en castellano) que se utiliza en lenguas opacas o semiopacas (p.ej. inglés y francés), se administró una prueba de escritura al dictado de palabras con grafonemas inconsistentes. Todas las palabras son de frecuencia alta para los escolares de los primeros cursos de educación primaria (Martínez \& García, 2004) de forma que, en ausencia de dificultades de aprendizaje, puedan formar parte de sus léxicos ortográficos.

Estímulos y procedimiento: La prueba se administró de forma colectiva y en la misma sesión que el test TECLE. Consta de una lista de 34 frases acabando cada una de ellas por una palabra de alta frecuencia que contiene alguno/s de los siguientes grafonemas inconsistentes: b/v (ej: barco, viento); g/j (con e o i, ej. genio, gigante) o h/no hache (hambre, idea), colocados en posición inicial o intermedia (excepto en el caso de h/no hache que siempre aparece al inicio). Los sujetos disponen de una hoja con un listado de 34 números junto a los que deben escribir tan sólo la última palabra de cada frase dictada, concediéndose un punto por cada grafonema inconsistente correctamente escrito (máximo 40, dado que algunas palabras contenían dos de los grafonemas estudiados). 


\section{RESULTADOS}

\section{Mecanismos de identificación de palabras en disléxicos}

En primer lugar presentamos los resultados de disléxicos y normolectores en las distintas pruebas administradas (Eficacia lectora, exactitud y velocidad en Lectura de palabras y pseudopalabras, y exactitud en Dictado) y seguidamente, analizamos las diferencias entre ambos grupos y en los diferentes cursos. En la tarea ortográfica las puntaciones directas se corrigieron para controlar los aciertos por azar, que son aproximadamente de $50 \%$. La fórmula aplicada para cada sujeto consiste en calcular la diferencia entre el número de aciertos obtenido y el de aciertos posibles por azar (20) y dividirla por la diferencia entre la puntación máxima posible (40) y la puntación esperable por azar. De esta forma las puntuaciones varían entre aproximadamente 0 , correspondiente al azar, y 1 cuando la ejecución es perfecta. Este puntaje es una transformación lineal de la puntuación directa ( $n^{\circ}$ de aciertos) y, por consiguiente, no modifica los cálculos estadísticos (anovas y correlaciones con las demás variables). Su introducción se justifica porque aporta una imagen mejor contrastada del nivel ortográfico de los sujetos.
En las tareas de lectura en voz alta se tomaron las puntaciones directas (número de respuestas correctas para exactitud y tiempo en segundos para velocidad). Sobre los resultados en cada variable se realizó un análisis de varianza considerando como factores intersujetos el Curso $\left(3^{\circ}, 4^{\circ}, 5^{\circ}\right.$ y $\left.6^{\circ}\right)$ y el Nivel lector (disléxicos y normolectores).

En la Tabla 2 se presentan los valores de $F$ y sus correspondientes niveles de significación (p).

Los resultados en Eficacia lectora, que se muestran en la Figura 1 (izquierda), revelan un retraso de aproximadamente tres años de los disléxicos respecto al grupo de normolectores. Los disléxicos de $6^{\circ}$ no alcanzan el nivel de los normolectores de $3^{\circ}$. Además, la interacción significativa Nivel lector y Curso indica que la diferencia entre los dos grupos tiende aumentar con el curso escolar.

En la Figura 1 (derecha) se representan las puntuaciones medias de disléxicos y normolectores en la tarea de dictado. También en este caso el retraso de los disléxicos sobrepasa los 3 años.

La interacción significativa entre Nivel lector y Curso carece de interés porque resulta de las puntuaciones atípicas de los disléxicos de $4^{\circ}$ curso, donde el limitado tamaño de este grupo, 7 sujetos, podría explicar el resultado.

Tabla 2. Medias y desviaciones típicas (S.D.) en disléxicos y normolectores en Eficacia lectora, Lectura de palabras, Lectura de pseudopalabras y Dictado. Valores de F y de significación de los análisis de varianza univariados, con Nivel Lector y Curso como variables intersujeto

\begin{tabular}{|c|c|c|c|c|c|}
\hline $\begin{array}{c}\text { Pruebas } \\
\text { administradas }\end{array}$ & $\begin{array}{c}\text { Disléxicos } \mathrm{N}=60 \\
\text { Media } \\
\text { S.D. }\end{array}$ & $\begin{array}{c}\text { Normolectores } \mathrm{N}=65 \\
\text { Media } \\
\text { S.D. }\end{array}$ & $\begin{array}{l}\text { Efecto Nivel } \\
\text { lector } \\
\text { Valores de F } \\
\text { g.l. }(1,117)\end{array}$ & $\begin{array}{c}\text { Efecto Curso } \\
\text { Valores de F } \\
\text { g.l. }(3,117)\end{array}$ & $\begin{array}{c}\text { Nivel lector*Curso } \\
\text { Valores de } F \\
\text { g.l. }(3,117)\end{array}$ \\
\hline $\begin{array}{l}\text { Eficicacia lectora- } \\
\text { TECLE }\end{array}$ & $\begin{array}{r}14,37 \\
4,57\end{array}$ & $\begin{array}{c}30,45 \\
7,41\end{array}$ & $422,34^{\star \star *}$ & $65,47^{\star * *}$ & $7,07^{\star * *}$ \\
\hline $\begin{array}{l}\text { Aciertos palabras } \\
\text { (max:36) }\end{array}$ & $\begin{array}{r}26,07 \\
7,53\end{array}$ & $\begin{array}{c}34,91 \\
1,42\end{array}$ & $59.69^{\star \star *}$ & $3,36^{*}$ & $2,72^{*}$ \\
\hline $\begin{array}{l}\text { Tiempo en } \\
\text { palabras (seg.) }\end{array}$ & $\begin{array}{l}66,40 \\
41,05 \\
\end{array}$ & $\begin{array}{c}26,95 \\
7,03\end{array}$ & $35,66^{\star \star *}$ & $3,47^{* *}$ & n.s. \\
\hline $\begin{array}{l}\text { Índice lectura } \\
\text { palabras }\end{array}$ & $\begin{array}{l}0,53 \\
0,32\end{array}$ & $\begin{array}{l}1,37 \\
0,33\end{array}$ & $169,20^{* * *}$ & $6,31^{* * *}$ & n.s. \\
\hline $\begin{array}{l}\text { Aciertos pseudo- } \\
\text { pal. (max:36) }\end{array}$ & $\begin{array}{c}15,63 \\
8,66\end{array}$ & $\begin{array}{r}24,58 \\
6,01\end{array}$ & $43,05^{\star \star \star}$ & $3,38^{*}$ & n.s. \\
\hline $\begin{array}{l}\text { Tiempo en pseudo- } \\
\text { pal. (seg.) }\end{array}$ & $\begin{array}{c}107,72 \\
42,44\end{array}$ & $\begin{array}{l}64,48 \\
13,28\end{array}$ & $44,14^{\star * *}$ & $4,91^{* *}$ & n.s. \\
\hline $\begin{array}{l}\text { Índice lectura } \\
\text { pseudopalabras }\end{array}$ & $\begin{array}{l}0,16 \\
0,10\end{array}$ & $\begin{array}{l}0,40 \\
0,14\end{array}$ & $109,11^{* * *}$ & $8,80^{* * *}$ & n.s. \\
\hline $\begin{array}{l}\text { Dictado palabras } \\
\text { (\% aciertos) }\end{array}$ & $\begin{array}{l}49,8 \\
25,1\end{array}$ & $\begin{array}{l}85,6 \\
16,6\end{array}$ & $61,16^{\star \star \star}$ & $9,00^{* * *}$ & $4,07^{* *}$ \\
\hline
\end{tabular}

${ }^{* * *} p<0,001 ;{ }^{* *} p<0,01 ;{ }^{*} p<0,05$ 
No obstante, un nuevo análisis de varianza excluyendo el $4^{\circ}$ curso, mostró un valor de $F=3,06$ marginalmente significativo $(p=0,051)$. La explicación de esta tendencia parece estar en el efecto techo encontrado en las puntuaciones de los normolectores que se aproximan al $100 \%$ de aciertos en $5^{\circ}$ y $6^{\circ}$ curso.

Observamos por tanto que, con el avance de la escolaridad, el nivel de eficiencia lectora de los disléxicos así como sus conocimientos ortográficos, avanzan tan lentamente que no logran acercarse al nivel de los normolectores, por el contrario la distancia tiende a aumentar.
Los resultados en las tareas de lectura de palabras y de pseudopalabras aparecen en la Figura 2 (exactitud) y en la Figura 3 (tiempo). Los efectos principales, Nivel lector y Curso, son en todos los casos altamente significativos y no necesitan comentario. La interacción entre Nivel lector y Curso que se observa en Lectura de palabras con los aciertos se debe al efecto techo en los normolectores, que prácticamente no comenten errores en esta condición.

Aunque es interesante examinar de forma independiente las medidas de exactitud y de tiempo, hemos de considerar que estas últimas
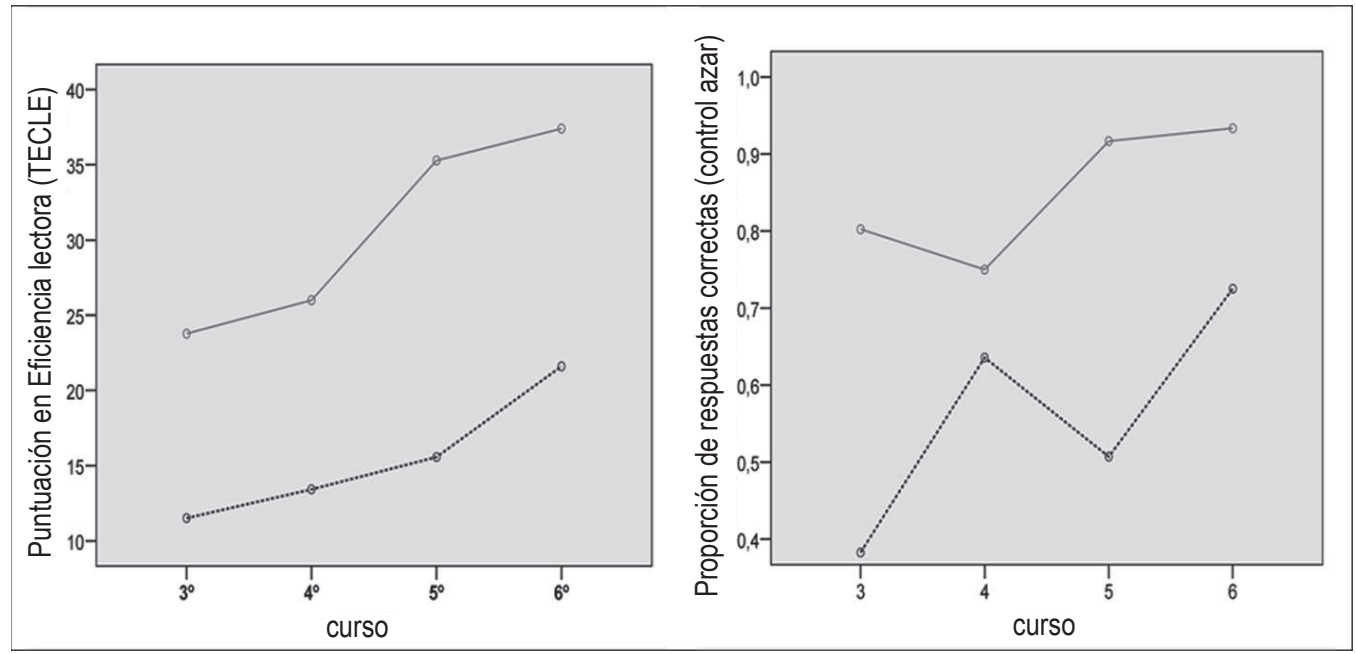

Figura 1. Evolución de $3^{\circ}$ a $6^{\circ}$ curso de la media en Eficiencia lectora (izda.) y Dictado (dcha.) según Nivel Lector (línea continua normolectores; línea punteada disléxicos)

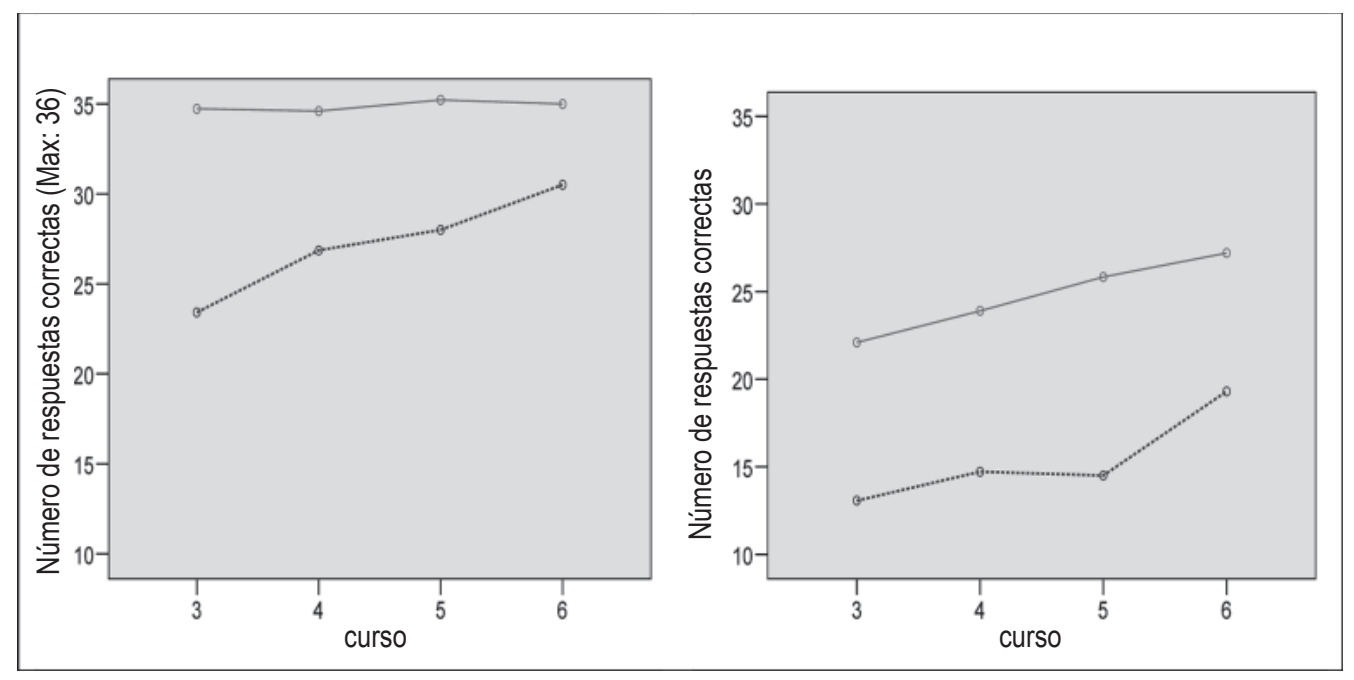

Figura 2. Evolución de $3^{\circ}$ a $6^{\circ}$ curso de la media en exactitud de Lectura de palabras (izda.) y Lectura de pseudopalabras (dcha.) según Nivel Lector (línea continua normolectores; línea punteada disléxicos) 


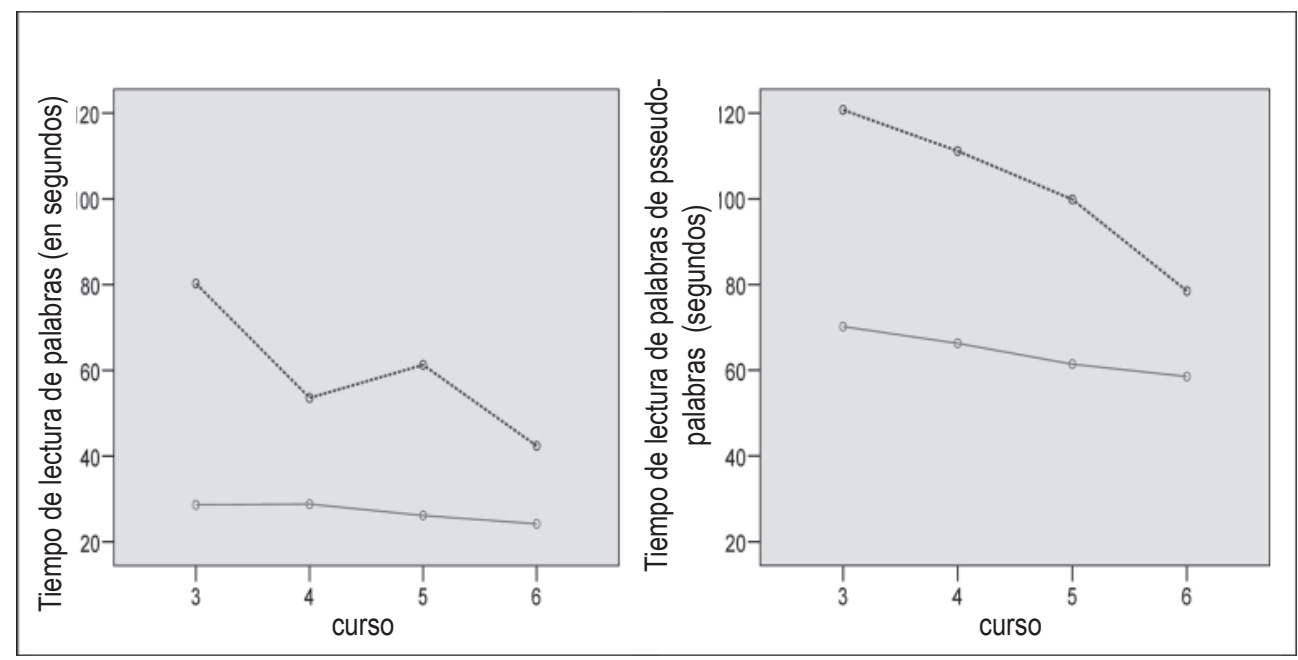

Figura 3. Evolución de $3^{\circ}$ a $6^{\circ}$ curso de la media en tiempo de Lectura de palabras (izda.) y Lectura de pseudopalabras (dcha.) por Nivel Lector (línea continua normolectores; línea punteada disléxicos)

se refieren a la lectura de la lista completa de ítems, con independencia de que la lectura fuera correcta o incorrecta, por lo que la velocidad no es necesariamente un buen indicador del grado de dominio de la tarea. Sin embargo, una medida de eficiencia, integrando tiempo y exactitud en un puntaje único, podría reflejar con mayor fidelidad el grado de desarrollo de los mecanismos de identificación de palabras y pseudopalabras. Previamente, cabe considerar que la relación entre exactitud y velocidad puede tomar dos formas diferentes. Una consiste en intercambiar sus valores: el lector puede leer rápidamente cometiendo muchos errores, o bien lentamente y con exactitud. En el segundo caso, la velocidad y la exactitud covarían: un buen lector leerá rápido y con exactitud, mientras que un mal lector será lento y cometerá gran número de errores. Para saber cuál de las dos fórmulas es la que mejor se ajusta a nuestros resultados calculamos la correlación entre exactitud y tiempo. Esta correlación alcanzó un valor de $r=-, 797(p<0,001)$ en el caso de la lectura de palabras y $r=-, 515(p<0,001)$ en el caso de las pseudopalabras. El control de la variable Curso en el análisis de correlación parcial no modifica los resultados anteriores $(r=-, 714$; $p<0,001$ y $r=-, 462 ; p<0,001$ respectivamente), lo cual corrobora que no existe una función de intercambio entre velocidad y exactitud. En nuestra muestra, los buenos lectores fueron rápidos y precisos $\mathrm{y}$, por el contrario, los malos lectores fueron lentos e imprecisos, por lo que calculamos un índice de eficiencia dividiendo el $n^{\circ}$ de aciertos por el tiempo en segundos en cada sujeto, y tanto en la lectura de palabras como de pseudopalabras. La distribución de frecuencias en estas dos nuevas variables presentan una configuración típicamente normal, avalada por el ajuste obtenido al aplicar el test de normalidad de Kolmogorof-Smirnov tanto en palabras como en pseudopalabras (KS=0,852 y $\mathrm{KS}=0,941$, respectivamente).

En la tabla 2 se muestran las medias y desviaciones típicas en disléxicos y normolectores, así como los resultados de los análisis de varianza para estas nuevas variables. En ambos Índices de eficiencia (palabras y pseudopalabras) se obtuvo un efecto altamente significativo del Nivel lector y del Curso.

La diferencia entre normolectores y disléxicos es superior a tres años de escolaridad (véase figura 4); los disléxicos de $6^{\circ}$ están muy por debajo de los normolectores de $2^{\circ}$, lo que constituye una indicación favorable para el uso de este índice que discrimina mejor entre los grupos de lectores que cada uno de sus componentes considerados separadamente. Además, tal como se aprecia en la figura 4, no se observan fenómenos de suelo ni de techo, lo cual da mayor consistencia a la ausencia de interacción entre Curso y Nivel lector, indicando, por tanto, que la diferencia entre disléxicos y normolectores no evoluciona con el curso.

En particular, los disléxicos no tienden a alcanzar a los normolectores con el transcurso del tiempo. 


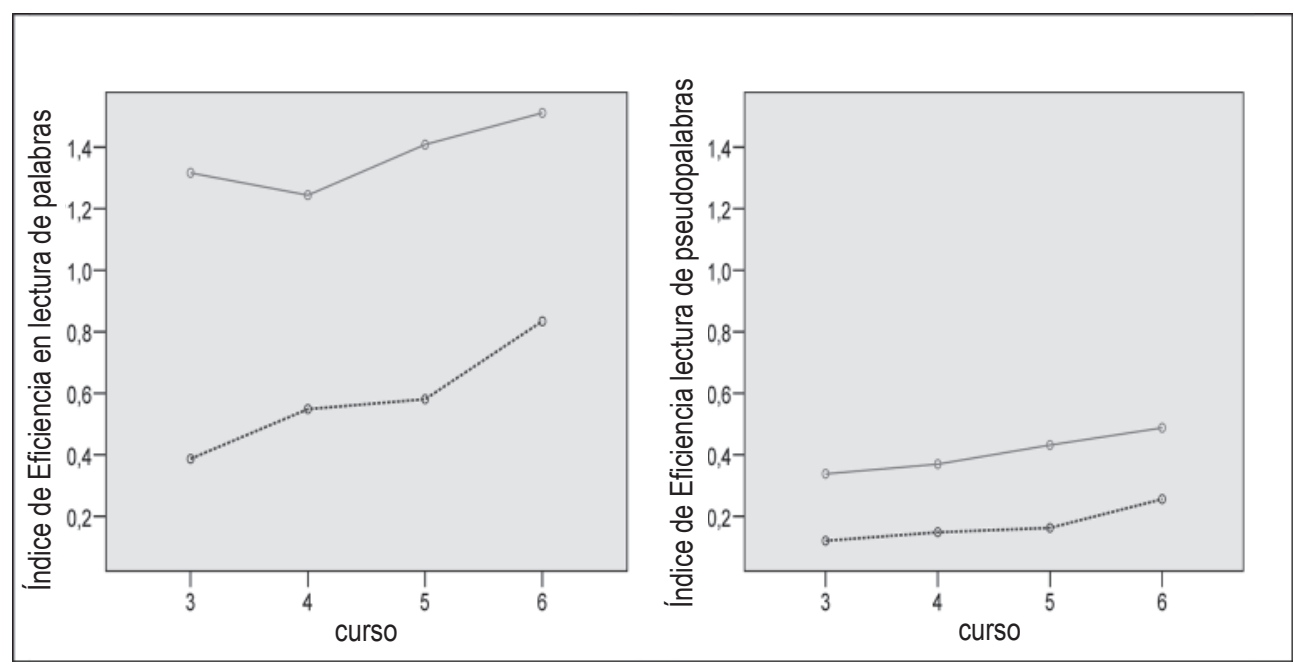

Figura 4. Evolución de $3^{\circ}$ a $6^{\circ}$ curso de la media en Índices de Eficiencia en lectura de palabras (izda.) y Eficiencia en lectura de pseudopalabras (dcha.) por Nivel lector (línea continua normolectores; línea punteada disléxicos)

Una vez establecida la diferencia entre disléxicos y normolectores a nivel de lectura de palabras y pseudopalabras separadamente, es importante examinar la diferencia que pueda existir si se comparan entre sí ambas tareas. El efecto de lexicalidad hace referencia al hecho de que las palabras se leen más eficientemente que las pseudopalabras porque hacen intervenir el mecanismo léxico-ortográfico. Un efecto de lexicalidad bajo en disléxicos, con respecto los normolectores, sería indicativo de un deterioro en dicho mecanismo.

Por otra parte, el efecto de longitud hace referencia a la mayor facilidad en el procesamiento de ítems cortos con respecto a los largos. Este efecto pone en evidencia la eficacia del mecanismo de ensamblaje fonológico y se espera que sea más acentuado en los disléxicos en quienes este mecanismo no está automatizado. Finalmente, el ensamblaje fonológico tiene un efecto mayor en el procesamiento de pseudopalabras que en el de palabras, lo que permite prever una interacción entre Longitud y Lexicalidad.

En nuestro estudio, el efecto de lexicalidad fue evaluado comparando los Índices de eficiencia lectora de palabras y pseudopalabras.

La Figura 5 representa dicho efecto en los dos grupos de lectores. Un análisis de varianza 2X2 tomando como factor intersujeto el Nivel lector (disléxicos vs. normolectores) y como factor intrasujetos la Lexicalidad (palabras vs. pseudopalabras) muestra que la interacción entre los dos factores es altamente significativa $(F(1,123)=122,61 ; p<0,001)$. El interés principal de este análisis es el de mostrar un efecto de lexicalidad inferior en los disléxicos si se compara con el obtenido en los normolectores. Los disléxicos tienden a leer las palabras de manera muy similar a las pseudopalabras y, por tanto, con una fuerte intervención del mecanismo de ensamblaje fonológico, al carecer de un desarrollo suficiente del léxico ortográfico.

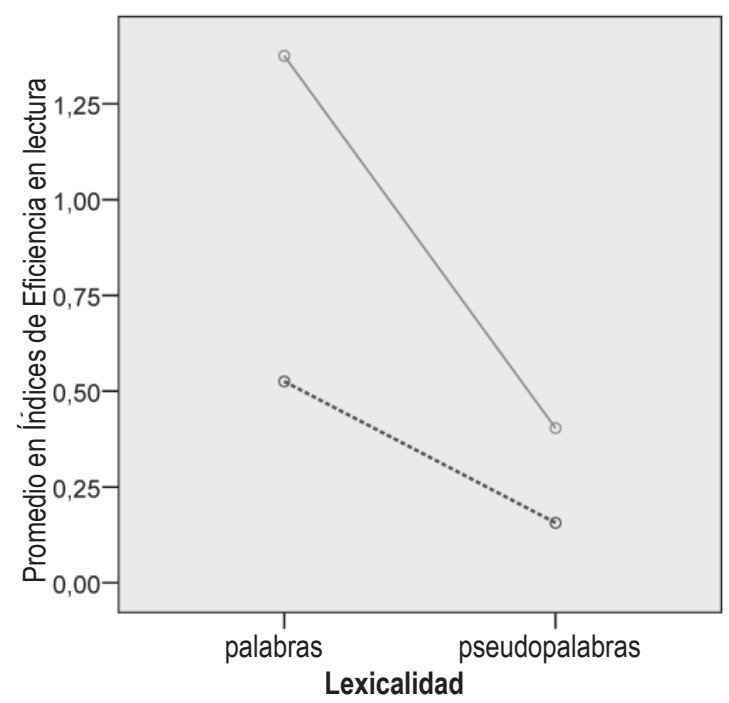

Figura 5. Efecto de Lexicalidad por Nivel lector (disléxicos y normolectores) en los Índices de eficiencia en lectura de palabras y pseudopalabras 
Para examinar el efecto de longitud sólo pudimos utilizar las medidas de exactitud en lectura, puesto que los tiempos no fueron medidos ítem por ítem sino sobre el conjunto de la lista. En la Figura 6 se representan los promedios del número de aciertos en lectura de palabras y pseudopalabras en función de la longitud de los ítems en disléxicos (izquierda) y normolectores (derecha). Realizamos un análisis de varianza 2X3X2 sobre la variable exactitud tomando el factor intersujeto Nivel Lector (disléxicos vs. normolectores) y los factores intrasujeto Longitud (bisilábicas, trisilábicas, tetrasilábicas) y Lexicalidad (palabras vs. pseudopalabras). EI efecto de Longitud, al igual que el de Lexicalidad (ya comentado), resultó altamente significativo $(F(2,123)=176,82 ; p<0,001)$. Pero, contrariamente a lo esperado, la interacción entre Longitud y Nivel lector resultó no significativa. Esto es probablemente debido al hecho de que en el grupo de normolectores la lectura de pseudopalabras monosilábicas (al igual que la lectura de palabras) alcanza el nivel de techo, lo que impide que aparezca un efecto más importante de longitud con pseudopalabras en este grupo. Se confirma de nuevo la menor fiabilidad de los aciertos si se compara con la del índice de eficiencia. La interacción entre Longitud y Lexicalidad resultó altamente significativa $(F(2,123)$ $=91,02 ; p<0,001)$ indicando que la longitud no afecta por igual a palabras y pseudopalabras. La Figura 6 muestra que en ambos grupos de lectores la longitud prácticamente no afecta a la exactitud de la lectura de palabras.
Por último, la triple interacción entre Longitud, Lexicalidad y Nivel lector estuvo próxima a la significación $(F(2,123)=2,83 ; p=0,061)$.

\section{Identificación de subtipos de disléxicos}

Los resultados anteriores ponen en evidencia las características de los mecanismos de identificación de palabras de nuestra muestra de disléxicos tomados conjuntamente.

El objetivo siguiente es establecer la existencia de diferentes tipos de disléxicos, en particular fonológicos y de superficie que, además de presentar un atraso global en lectura, presentan un perfil fuera de las normas en cuanto a la utilización de los mecanismos fonológico y ortográfico. Siguiendo el método de regresión descrito precedentemente, se calculó la regresión de las puntaciones en Dictado en función del Índice de eficacia en lectura de pseudopalabras de los normolectores, así como la regresión contraria.

En las Figuras $7 a$ y $7 b$ se representan los límites inferiores del intervalo de confianza $(p=.95)$ de cada regresión (los respectivos límites superiores quedan fuera de los gráficos) si bien, las puntuaciones que aparecen marcadas son las de los disléxicos. Los casos que se sitúan fuera de alguno de los límites tienen un déficit excesivo en la correspondiente competencia de base. Veinticinco casos $(42 \%$ de los disléxicos) se sitúan en la tarea de dictado por debajo del límite y pueden ser considerados disléxicos de superficie (figura 7a).
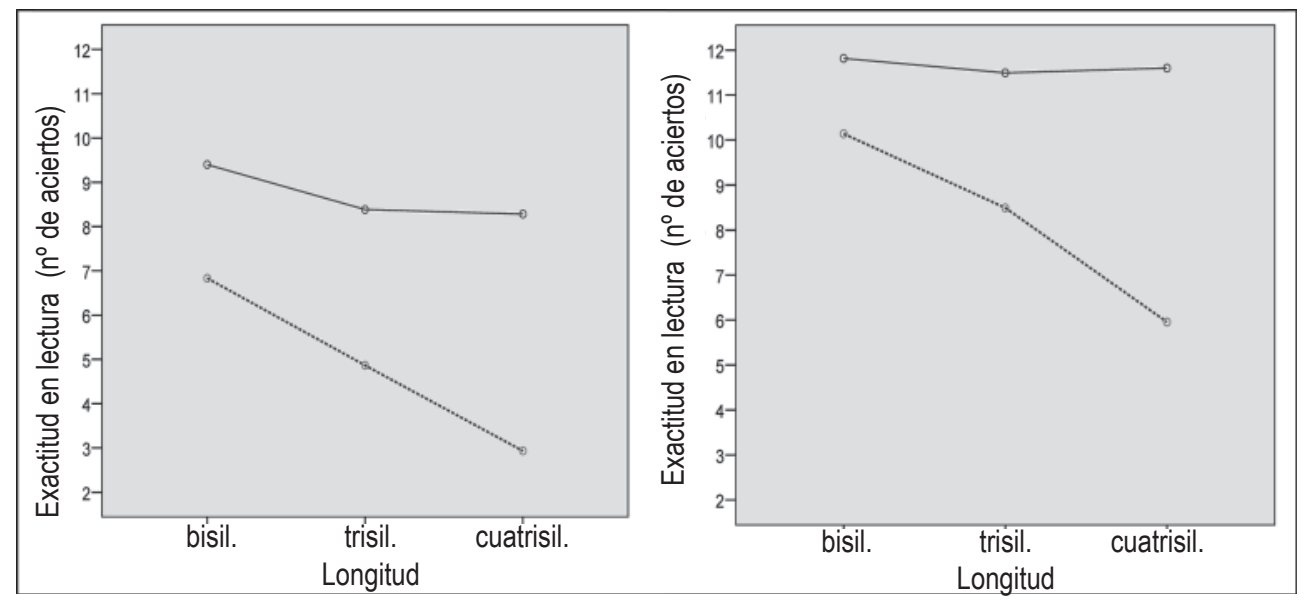

Figura 6. Interacción entre Lexicalidad y Longitud en la variable exactitud de Lectura de palabras (línea continua) y Lectura de pseudopalabras (línea punteada). En disléxicos (izquierda) y normolectores (derecha) 
De la misma manera 5 casos (8\% de los disléxicos) presentan un índice de eficiencia lectora en pseudopalabras por debajo del límite y pueden ser considerados disléxicos fonológicos (Figura 7b).

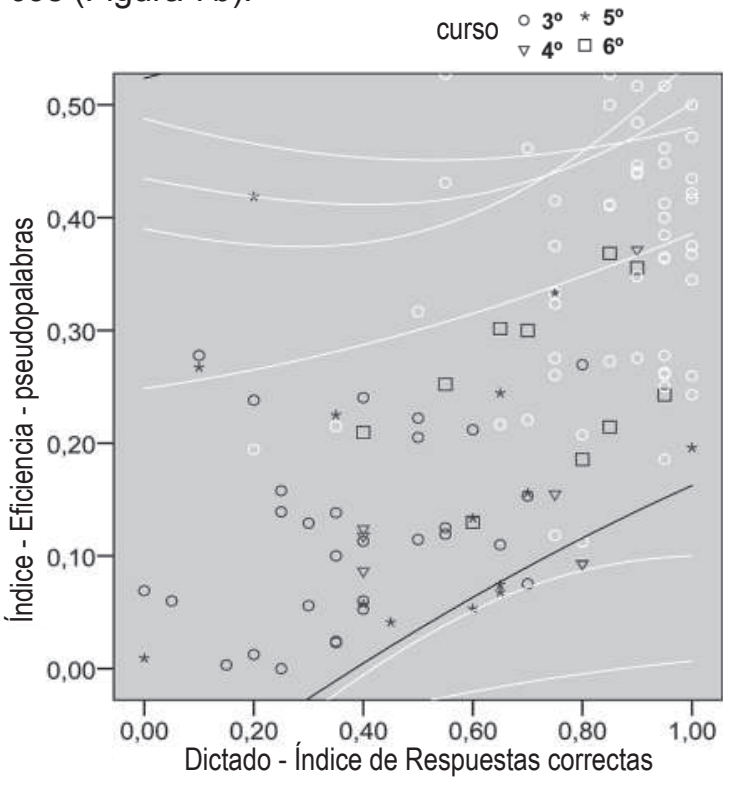

Figura 7a. Puntuaciones en Dictado, en función de la Eficiencia en lectura de pseudopalabras. Las marcas corresponden al grupo de disléxicos. La línea es el límite inferior del intervalo de confianza (95\%) de la regresión derivada de los datos de los normolectores de la misma edad. Los disléxicos situados bajo la línea se identifican como disléxicos de superficie

El resto de los disléxicos (50\%) se sitúan dentro de los límites de confianza, por lo que presentan un retraso "armónico".

Es interesante hacer notar que los disléxicos de superficie presentan puntuaciones en la tarea de dictado francamente por debajo del límite admisible establecido con los normolectores, no así los disléxicos fonológicos cuyas puntuaciones en el índice de eficiencia lectora en pseudopalabras está justo al límite de confianza (Figura 7b).

Los análisis de subtipos de disléxicos disponibles en la literatura (p.ej. Calvo, 1999; Cuadro \& Marín, 2007; Genard et al., 1998; Manis et al., 1996; Stanovich et al., 1997), además de comparar estos grupos con normolectores de la misma edad (grupo de "control edad"), suelen compararlos también con normolectores que presentan el mismo nivel lector y que por consiguiente son más jóvenes (grupo de "control lector").
Se ha observado en la mayoría de estos estudios que el perfil de superficie corresponde al de los lectores jóvenes del mismo nivel lector, lo que hace pensar que estos disléxicos tienen un simple atraso en lectura, no así los disléxicos fonológicos cuya deficiencia en el nivel del mecanismo fonológico está también fuera del límite establecido con los resultados del grupo de lectores jóvenes.

Siguiendo este procedimiento se presentan en la Tabla 3 los resultados de los diferentes subgrupos de disléxicos junto con los de un grupo de normolectores de $2^{\circ}$ curso.

Junto a las puntuaciones en Eficacia lectora y en las variables tomadas para evaluar el funcionamiento de los dos mecanismos de identificación de palabras (Índice de eficiencia en lectura de pseudopalabras e Índice de exactitud en la prueba de dictado) se han incluido los puntajes independientes de exactitud y tiempo en lectura de pseudopalabras así como el Índice de eficiencia lectora en palabras, porque aportan informaciones interesantes.

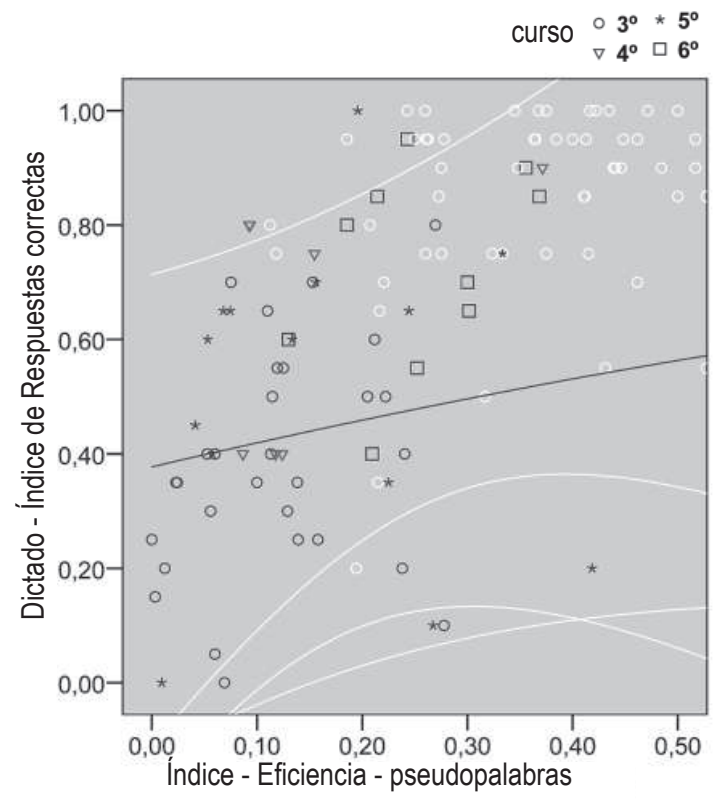

Figura 7b. Puntuaciones de Eficiencia en lectura de pseudopalabras, en función de la puntuación en Dictado. Las marcas corresponden al grupo de disléxicos. La línea es el límite inferior del intervalo de confianza (95\%) de la regresión derivada de los datos de los normolectores de la misma edad. Los disléxicos situados bajo la línea se identifican como disléxicos fonológicos 
Tabla 3. Medias y desviaciones típicas (S.D.) en Eficacia lectora, Lectura de palabras, Lectura de pseudopalabras y Dictado en disléxicos armónicos, fonológicos y de superficie y en el grupo control lector (normolectores de $2^{\circ}$ )

\begin{tabular}{|c|c|c|c|c|c|c|c|c|}
\hline & \multicolumn{2}{|c|}{$\underset{N=30}{\text { A r m ó n i cos }}$} & \multicolumn{2}{|c|}{$\begin{array}{c}\text { Fonológicos } \\
\mathrm{N}=5\end{array}$} & \multicolumn{2}{|c|}{$\begin{array}{c}\text { S u p e r f i c i e } \\
N=25\end{array}$} & \multicolumn{2}{|c|}{$\begin{array}{c}\text { Normolec }-2^{\circ} \\
N=15\end{array}$} \\
\hline & Media & S.D. & Media & S.D. & Media & S.D. & Media & $S . D$. \\
\hline Efic. Lectora & 16,3 & 4,7 & 15,2 & 3,2 & $11,8^{*}$ & 3,4 & 19,3 & 3,9 \\
\hline Ind-Dictado & 0,67 & 0,17 & 0,68 & 0,07 & $0,26^{* *}$ & 0,13 & 0,52 & 0,23 \\
\hline Ac-Pseudopal & 16,6 & 7,5 & 8,8 & 5,2 & 13,4 & 9,9 & 23,9 & 6,6 \\
\hline Tiemp-Pseudopal & 91,9 & 22,4 & 115,4 & 43,6 & $125,2^{*}$ & 53,5 & 80,1 & 14,9 \\
\hline Ind-Efic-Pseud. & 0,19 & 0,10 & 0,07 & 0,01 & 0,12 & 0,10 & 0,32 & 0,12 \\
\hline Ind-Efic-Palab. & 0,69 & 0,32 & 0,44 & 0,26 & $0,35^{*}$ & 0,22 & 0,96 & 0,28 \\
\hline
\end{tabular}

Sólo están marcadas las diferencias significativas entre los tres grupos de disléxicos: $\left(^{*}\right)$ con armónicos y $\left(^{* *}\right)$ con armónicos y fonológicos.

El grupo de normolectores de $2^{\circ}$ obtiene mejor puntuación promedio que los grupos de disléxicos en todas las medidas, excepto en Dictado en la que es superado por disléxicos armónicos y fonológicos. Sobre cada una de las variables realizamos un análisis de varianza tomando como factor intersujetos el Grupo (los tres de disléxicos y el de jóvenes normolectores). En todos los casos este factor fue altamente significativo $(p<0,001)$. El examen de las diferencias dos a dos a través de comparaciones

(Bonferroni o Tamhane, según que las varianzas fueran o no homogéneas) mostró que la puntuación de $2^{\circ}$ curso en Eficacia lectora (19,3 aciertos en el test Tecle), aunque supera a la de los diferentes grupos de disléxicos, sólo se diferencia estadísticamente $(p<0,001)$ con respecto a los disléxicos de superficie $(11,8)$, que es el grupo de disléxicos que mostró peor puntuación en esta variable.

En la prueba de Dictado se repiten las mismas diferencias significativas que en Eficacia lectora: los disléxicos de superficie son peores que los normolectores de $2^{\circ}$ y que los armónicos. Así pues, el grupo de disléxicos de superficie muestra un importante retraso en su desarrollo ortográfico no sólo con respecto a los disléxicos fonológicos y armónicos, consecuencia directa del método que permitió constituir los grupos, sino también con respecto a los jóvenes normolectores de $2^{\circ}$.

En el Índice de eficiencia en lectura de pseudopalabras también esperamos, debido al método de clasificación, que los disléxicos fonológicos se distingan de los de superficie.
Sin embargo no se obtuvieron diferencias significativas en esta comparación, ni en ninguna de las establecidas entre grupos disléxicos. Sólo fueron significativas las comparaciones de $2^{\circ}$ curso con cada grupo de disléxicos y lo mismo ocurre cuando comparamos las medidas de exactitud en lectura de pseudopalabras.

En la medida de velocidad son los disléxicos de superficie los más lentos, diferenciándose significativamente del grupo de $2^{\circ}$ y de los armónicos, aunque no de los disléxicos fonológicos.

Para finalizar, examinamos la distribución de los disléxicos de cada subtipo por curso escolar.

La tabla 4 muestra que la mayor parte de los disléxicos de superficie (17 de los 29 casos) es de $3^{\circ}$, lo que podría explicar el menor nivel de Eficacia lectora y de desarrollo léxico-ortográfico de este grupo. Los fonológicos, por el contrario, son más escasos en $3^{\circ}$ y $4^{\circ}$ (un caso por curso) y los 3 restantes son de $5^{\circ}$, lo que podría explicar su mejor nivel ortográfico.

Tabla 4. Número y porcentaje de escolares de cada subtipo de dislexia según el curso escolar

\begin{tabular}{|c|cc|cc|cc|}
\hline $\begin{array}{c}\mathbf{N}^{0} \text { de disléxicos } \\
\text { por curso }\end{array}$ & \multicolumn{2}{|c|}{$\begin{array}{c}\text { Armónicos } \\
\mathbf{N}=\mathbf{3 0}\end{array}$} & $\begin{array}{c}\text { Fonológicos } \\
\mathbf{N}=\mathbf{5}\end{array}$ & \multicolumn{2}{|c|}{$\begin{array}{c}\text { Superficie } \\
\mathbf{N}=\mathbf{2 5}\end{array}$} \\
\hline $3^{\circ}(\mathrm{N}=\mathbf{2 9})$ & 11 & $38 \%$ & 1 & $3 \%$ & 17 & $59 \%$ \\
\hline $4^{\circ}(\mathrm{N}=7)$ & 3 & $43 \%$ & 1 & $14 \%$ & 3 & $43 \%$ \\
\hline $5^{\circ}(\mathrm{N}=14)$ & 7 & $50 \%$ & 3 & $21 \%$ & 4 & $29 \%$ \\
\hline $6^{\circ}(\mathrm{N}=10)$ & 9 & $90 \%$ & \multicolumn{2}{|c|}{-} & 1 & $10 \%$ \\
\hline
\end{tabular}




\section{DISCUSIÓN}

La hipótesis central de este trabajo es que la causa inmediata de las dificultades de lectura de los disléxicos se encuentra, en primera instancia, en la calidad deficiente de sus mecanismos de identificación de palabras escritas. Los resultados de nuestro estudio que están directamente en relación con esta hipótesis son claros: Los disléxicos, detectados por su falta de eficiencia lectora con una prueba de lectura en voz baja de frases (Test Tecle), presentan en promedio un retraso superior a tres años en la tarea de lectura en voz alta de palabras aisladas. Este retraso, según las teorías vigentes (Coltheart, Curtis, Atkins \& Haller, 1993; Paap \& Noel, 1991), puede ser debido a problemas en alguno de los dos mecanismos de identificación de palabras, grafo-fonológico u ortográfico-lexical, o en ambos. Por otra parte, la teoría de autoenseñanza (Share, 1995) supone que la actividad del primero de ellos genera progresivamente las representaciones ortográficas necesarias para el funcionamiento del segundo.

En este trabajo utilizamos la tarea de lectura de pseudopalabras con el fin de explorar lo más directamente posible la destreza fonológica de los escolares y los resultados muestran también un retraso importante a este nivel, que es superior a los 3 años. La lectura de palabras y pseudopalabras explican una porción considerable de la varianza en el test de lectura de frases (véase, Carrillo \& Alegría, 2009). La noción de que la identificación de palabras realizada gracias a la actividad de ensamblaje fonológico determina el desarrollo del léxico ortográfico, permite predecir que cuando el primero es débil el segundo lo será también. Los resultados confirman claramente esta predicción.

El efecto de lexicalidad, es decir, la ventaja en la lectura de palabras con respecto a la lectura de pseudopalabras, es muy superior en los normolectores frente a los disléxicos; además, en estos últimos la diferencia entre leer palabras y pseudopalabras es pequeña. Los disléxicos son peores leyendo pseudopalabras porque su mecanismo fonológico es deficiente y como consecuencia el léxico ortográfico se desarrolla con dificultad.

Por esta razón, la lectura de palabras no alcanza los altos niveles que logran los normolectores. En conjunto estos resultados son perfectamente coherentes y en conformidad con la hipótesis del déficit fonológico.

La investigación que se ha interesado en la comparación del proceso de adquisición de los mecanismos de identificación de palabras ha demostrado que este proceso es más rápido en los sistemas transparentes como el del castellano.

Una precaución en nuestro trabajo fue medir la velocidad de lectura de palabras y pseudopalabras y no sólo la exactitud de esta operación. La razón es que en otras lenguas transparentes, como la alemana, se ha observado que los disléxicos son capaces de leer sin producir apenas errores pero que lo hacen lentamente (Wimmer, Mayringer \& Landerl, 1998).

Los resultados obtenidos aquí no confirman esta idea. El número de aciertos leyendo tanto palabras como pseudopalabras en los disléxicos es francamente inferior al de los normolectores, pero es probable que esto sea debido a que también los denominados errores leves (p.ej. silabeo marcado) fueron considerados como tales y a que la instrucción en la tarea de lectura era leer sin errores pero en el menor tiempo posible. También los resultados obtenidos en velocidad muestran un déficit importante en los disléxicos, ya que sus tiempos de lectura resultaron ser considerablemente más lentos que los de los normolectores. Además, la correlación entre estas dos medidas resultó negativa, mostrando que los buenos lectores leen rápido y tienen un alto porcentaje de aciertos, contrariamente a los malos lectores que son lentos e imprecisos. Esta observación nos llevó a calcular una nueva variable que combina las dos. Esta variable se mostró más adecuada para dar cuenta de la capacidad de los sujetos que cada una de los dos componentes tomadas separadamente. Todo el razonamiento que precede fue llevado a cabo utilizando esta medida.

Nuestro objetivo era también establecer la posible heterogeneidad entre los disléxicos y más particularmente mostrar la presencia de los dos tipos "disarmónicos" - fonológicos y de superficie - identificados en lenguas opacas como el inglés (Castles \& Coltheart, 1993; Manis et al., 1996; Stanovich et al., 1997), no así en lenguas transparentes como el castellano (Calvo, 1999; Carrillo, Calvo \& Alegría, 2007; Carrillo, Alegría \& Calvo, 2008). Al igual que en los citados estudios, aplicamos el denominado método de regresión si bien las tareas utilizadas para evaluar el funcionamiento de los dos mecanismos de identificación de palabras difieren 
con el fin de acomodarse a las características ortográficas del español. En los estudios realizados en lenguas opacas como el inglés y el francés la evaluación del mecanismo ortográfico se realiza con una tarea de lectura de palabras irregulares (que no pueden leerse correctamente por el mecanismo fonológico).

En castellano no hay palabras irregulares en lectura pero sí en escritura, lo cual ocurre cuando la ortografía de una palabra no puede ser derivada de su fonología y, por consiguiente, en la escritura de estas palabras es necesaria la utilización de representaciones ortográficas. En cuanto a la evaluación del funcionamiento del mecanismo fonológico, las lenguas opacas utilizan la exactitud en lectura de pseudopalabras. Este puntaje es menos discriminativo en castellano como acabamos de comentar (véase también Serrano \& Defior, 2005). La medida adoptada finalmente fue el Índice de eficiencia en lectura de pseudopalabras que combina velocidad y exactitud y refleja mejor las diferencias individuales en descodificación fonológica.

Las ecuaciones de regresión fueron establecidas con el grupo de normolectores de la misma edad y nivel escolar que los disléxicos.

Estas definen las relaciones supuestamente normales de las puntuaciones en la tarea de dictado (que evalúa el mecanismo ortográfico) en función del Índice de eficacia en lectura de pseudopalabras (que evalúa el mecanismo fonológico) y viceversa. En cada una de estas dos ecuaciones se establecieron los límites de confianza que incluyen al $95 \%$ de los normolectores y las variaciones en el interior de estos límites se consideran normales. Las puntuaciones de la mitad de los disléxicos (30 casos) se sitúan dentro de ambos límites de normalidad, es decir, que sus capacidades fonológicas predicen correctamente sus capacidades ortográficas y viceversa, mientras que las puntuaciones de la otra mitad quedaban fuera de uno de los dos límites. En 25 de estos casos la puntuación en la prueba de dictado estaba por debajo de lo previsible a partir de las correspondientes puntuaciones en lectura de pseudopalabras (perfil de superficie) mientras que en los 5 casos restantes ocurría lo contrario: la puntuación en lectura de pseudopalabras quedaba por debajo del límite previsible a partir de las puntuaciones alcanzadas en la prueba de dictado (perfil fonológico). La incidencia de disléxicos de superficie coincide con los resultados obtenidos en inglés, en francés y en otros estudios en español.

La presencia de este síndrome sugiere que la actividad del mecanismo fonológico de identificación de palabras es condición necesaria para el desarrollo del léxico ortográfico, pero no es suficiente. Aunque la capacidad de ensamblaje sea la misma, ciertos lectores pueden presentar diferencias importantes en la capacidad de memorización de palabras escritas.

El caso de los disléxicos fonológicos es más difícil de integrar en las predicciones de la teoría de autoenseñanza. Estos disléxicos tienen un nivel de procesamiento fonológico por debajo del nivel previsible a partir de sus capacidades ortográficas, o dicho de otra forma, su léxico ortográfico es más rico que lo previsible tomando en cuenta su capacidad fonológica. Los estudios realizados en inglés muestran la presencia de un porcentaje alto de disléxicos fonológicos (entre 55 y $25 \%$ según los casos).

En nuestro estudio, así como en el realizado en francés por Genard et al. (1998), este porcentaje es considerablemente inferior y, además, en ambos estudios un aspecto importante de los resultados es que estos disléxicos se sitúan muy cerca del límite de normalidad, tal como se observa en la Figura 7b. Esto podría llevar a formular la hipótesis que la dislexia fonológica de desarrollo solo se observa en lenguas opacas como el inglés.

El francés lo es también pero solamente en la escritura y no en la lectura. Recuérdese que la formación de representaciones ortográficas de las palabras en el modelo de autoenseñanza depende del ensamblaje fonológico y, por consiguiente, de la consistencia del código alfabético al leer. Se podría formular la hipótesis de que en lenguas como el inglés, inconsistentes en lectura, existe una presión fuerte del sistema para que los lectores elaboren representaciones ortográficas de las palabras para ayudarse a la hora de leer.

El almacenamiento de información ortográfica sería consciente en estos casos y no la consecuencia automática de la identificación de palabras escritas. Esta hipótesis, puramente especulativa, necesita por supuesto verificación experimental.

La comparación de los disléxicos con los normolectores de $2^{\circ}$ muestra que los tres subgrupos de disléxicos presentan un déficit de procesamiento fonológico importante. Esto se observa en las puntuaciones de exactitud 
pero resulta particularmente claro con el Índice de eficiencia en lectura de pseudopalabras que combina exactitud y tiempo.

En este índice, los grupos de disléxicos no difieren entre sí a pesar de que los fonológicos presentan la tendencia esperada. Sin duda, su reducido número es responsable de que los resultados no alcancen el nivel de significación.

El rasgo característico de los disléxicos de superficie, que los distingue de los otros grupos disléxicos, es su nivel en la tarea de dictado, en la que se muestran por debajo incluso de los normolectores de $2^{\circ}$. Es interesante agregar que también son los peores cuando se comparan los Índices de eficiencia en lectura de palabras. Estas dos tareas, dictado y lectura de palabras, ponen en juego las representaciones léxicoortográficas que parecen constituir la deficiencia principal del grupo de disléxicos de superficie. Sin olvidar que este grupo presenta también problemas en el mecanismo fonológico cuando se lo compara con normolectores de $2^{\circ}$.

El examen de la distribución de los disléxicos en los cursos aporta informaciones interesantes en cuanto a la evolución de los subgrupos.

El rasgo característico de esta distribución es el aumento de la proporción de disléxicos "armónicos" con el curso y la disminución correlativa de los de superficie (es difícil hablar de tendencias en los disléxicos fonológicos a causa de su reducido número). Esto indica que con la edad y/o la escolaridad los subgrupos que presentan "desarmonías" en el desarrollo de los mecanismos de identificación de palabras tienden a desaparecer.

Concretamente se observa que, con el tiempo, el déficit léxico-ortográfico de los disléxicos de superficie se reduce. Esto es compatible con la teoría de autoenseñanza si se supone que, con una capacidad fonológica determinada, ciertos lectores necesitan más ensayos que otros para almacenar la información ortográfica de las palabras.

Sería interesante saber si el desarrollo del léxico ortográfico de los disléxicos de superficie va acompañado de una manera concomitante de un mejor funcionamiento del mecanismo fonológico, pero para explorar esta noción habría que disponer de datos longitudinales.

\section{REFERENCIAS}

Alegría, J., Marín, J., Carrillo, MS. \& Mousty, Ph. (2003). Les premiers pas dans l'acquisition de l'orthographe en fonction du caractère profond ou superficiel du système alphabétique: comparaison entre le français et l'espagnol. En M.N. Romdhane, J.E. Gombert, \& M. Belajouza (Eds), L'apprentissage de la lecture: Perspective comparative interlangues, pp. 51- 67. Presses Universitaires de Rennes.

Alegría J. \& Mousty, P. (2004). Les déficits phonologiques et métaphonologiques chez l'enfant dyslexique. Enfance, 3, 259-271.

Beauvois, M.F., \& Derouesné, J. (1979). Phonological alexia: three dissociations. Journal of Neurology, Neurosurgery, and Psychiatry, 42: 1115-1124.

Bowers, P.G. \& Wolf, M. (1993). Theoretical links among naming speed, précising timing mechanisms and orthographic skill in dyslexia. Reading \& Writing, 5, 69-85.

Brady, S. (1991). The role of working memory in reading disability. En S. Brady y D. Shankweiler (Eds). Phonological Processes in Literacy: A tribute to Isabelle Liberman (pp. 129-151). Hillsdale, N. J., Lawrence Erlbaum Associates.

Calvo, A.R. (1999). Adquisición de la lectura en lengua castellana: Perfiles cognitivos de aprendices con dificultades. Tesis Doctoral. Universidad de Murcia.

Campbell R, Butterworth B. (1985). Phonological dyslexia and dysgraphia in a highly literate subject: a developmental case with associated deficits of phonemic processing and awareness. Q J Experimental Psychology. 3, 435-75.

Carrillo, M.S. (en prensa). La evaluación de la dislexia evolutiva. En Carrillo, M. y Domínguez, A.B. Líneas actuales en el estudio de la lecto-escritura y sus dificultades: dislexia y sordera. Homenaje a Jesús Alegría. Ed. Aljibe

Carrillo, M.S. \& Alegría, J. (2009). Exploración de habilidades fonológicas en escolares disléxicos: teoría y práctica. Revista de Logopedia, Foniatría y Audiología, 29, 105-120.

Carrillo, M.S., Alegría, J. \& Calvo, A.R. (2008). Subtipos de dislexia en una ortografía transparente. Actas del XXIV Congreso Internacional de AESLA. Aprendizaje de lenguas, uso del lenguaje y modelación cognitiva: perspectivas aplicadas entre disciplinas. Madrid: UNED.

Carrillo, M.S., Calvo, A.R. \& Alegría, J. (2007). Variabilidad entre aprendices con dificultades en la lectura: ¿Diferentes subtipos o diferente estrategia lectora? En Sociedad de Dislexia del Uruguay (Ed.), 
Entre el sueño y la realidad: Nuestra América Latina alfabetizada (pp. 97-107). Montevideo. UNESCO.

Castles, A. \& Coltheart, M. (1993). Varieties of developmental dyslexia. Cognition, 47, 149-180.

Coltheart, M. (1981). Disorders of reading and their implications for models of normal reading. Visible Language, 15: 245-286.

Coltheart, M., Curtis, B., Atkins, P. \& Haller, M. (1993). Models of reading aloud: Dual-route and paralleldistributed-processing accounts. Psychological Review, 100, 589-608.

Coltheart, M., Masterson, J., Byng, S., Prior, M. \& Riddoch, M.J. (1983). Surface dyslexia. Quarterly Journal of Experimental Psychology, 35, 469-496.

Cuadro, A. \& Marín, J (2007). Subtipos de lectores retrasados en español. Ciencias Psicológicas, 1-2, 133-148.

Davies, R., Cuetos, F. \& González-Seijas, R. (2007). Reading development and dyslexia in a transparent orthography: a survey of Spanish children. Annals of Dyslexia. 57, 179-198.

Defior, S., Martos, F., \& Cary, L. (2002). Differences in reading acquisition development in two shallow orthographies: Portuguese and Spanish. Applied Psycholinguistics, 23, 135-148.

Denckla, M.B. \& Cutting, L. E. (1999). History and significance of Rapid Automatized Naming. Annals of Dyslexia, 49, 29-42.

Genard, N., Mousty, P., Content, A., Alegría, J., Leybaert, J. \& Morais, J. (1998). Methods to establish subtypes of developmental dyslexia. In P. Reitsma and L. Verhoeven (Eds). Problems and Interventions in Literacy Development. Dordrecht: Kluwer.

Goswami, U., Gombert, J.E. \& Fraca de Barrera, L. (1998). Children's orthographic representations and linguistic transparency: Nonsense word reading in English, French and Spanish. Journal of Applied Psycholinguistic, 19: 153-162.

Hoxhallari, L., van Daal, V.H.P. \& Ellis, N.C. (2004). Learning to read words in Albanian: A skill easily acquired. Reading \& Writing, 8: 153-166.

Jiménez, J.E, \& Ramírez, G. (2002). Identifying subtypes of reading disability in the Spanish language. The Spanish Journal of Psychology, 5: 3-19.

Landerl, K., Wimmwer, H. \& Frith, U. (1997). The impact of orthographic consistency on dyslexia. A GermanEnglish comparison. Cognition, 63: 315-334.

Maillart, C., Van Reybroeck, M \& Alegría, J. (2005). L'evaluation de la phonologie dans les troubles du langage oral: intérêt et perspectives. Le langage de l'enfant- développement et évaluation. Bruxelles: De Boeck.
Manis, F.R., McBride-Chang, C., Seidenberg, M., Keating, P., Doi, L. M., Munson, B. \& Petersen, A. (1997). Are speech perception deficits associated with developmental dyslexia? Journal of Experimental Child Psychology, 66, 211-235.

Manis, F.R., Seidenberg, M.S., Doi, L.M., McBride-Chang, C. \& Petersen, A. (1996). On the basis of two subtypes of developmental dyslexia. Cognition, 58, 157-195

Marín, J. \& Carrillo, M.S. (1997). Test de Eficiencia Lectora - TECLE. Publicado en A. Cuadro, D. Costa, D. Trias y P. Ponce de León, (2009) Evaluación del nivel lector. Manual técnico del test de Eficacia Lectora (TECLE). Uruguay, Prensa Médica Latinoamericana.

Martínez, J.A. (1995). La dyslexia evolutiva: un enfoque neuropsicológico. Tesis doctoral. Universidad de Salamanca.

Martínez, J. \& García, E. (2004): Diccionario de frecuencias del castellano escrito en niños de 6 a 12 años. Salamanca: Publicaciones Universidad Pontificia.

Marshall, J.C., \& Newcombe, F. (1973). Patterns of paralexia: a psycholinguistic approach. Journal of Psycholinguistic Research, 2: 175-199.

Morais, J. (1994). L'Art de Lire. Traducción castellana, El arte de leer (1998): Madrid: Visor.

Morton, J. \& Frith, U. (1995). Causal modelling: a structural approach to developmental psychopathology. In D. Cicchetti y D.J. Cohen (Eds), Manual of Developmental Psychopathology, pp. 357-390. New York: Wiley.

Paap, K.R. \& Noel, R. (1991). Dual route models of print to sound: Still a good horse race. Psychological Research, 53, 13-24.

Ramus, F. (2006). Genes, Brain and Cognition. Cognition Special Issue (Vol. 101). Amsterdam: Elsevier.

Ramus, F., Rosen, S., Dakin, S. C., Day, B. L., Castellote, J. M., White, S., \& Frith, U. (2003). Theories of developmental dyslexia: Insights from a multiple case study of dyslexic adults. Brain, 126, 841-865.

Serrano, F. \& Defior, S. (2005). Dyslexia in Spanish: the state of the matter. Electronic Journal of Research in Educational Psychology, 2 (2), 13-34.

Seymour, P.H.K., Aro, M. \& Erskine, J.M. (2003). Foundation literacy acquisition in European orthographies. British Journal of Psychology, 94: 143-174.

Share, D.L. (1995). Phonological recoding and self-teaching: Sine qua non of reading acquisition. Cognition, 55 (2), 151-218.

Share, D.L. (1999). Phonological recoding and orthographic learning: A direct test of the self-teaching hypothesis. Journal of Experimental Child Psychology, 72 (2), 95-129. 
Snowling, M. (2001). From language to reading and dyslexia. Dyslexia 7, 37-46.

Stanovich, K. (1996). Toward a more inclusive definition of dyslexia. Dyslexia, 2, 154-166.

Stanovich, K. (1998)Refining the phonological core deficitmodel. Child Psychology and Psychiatry Review, 1, 17-21.

Stanovich, K.E., Siegel, L.S., Gottardo, A., Chiappe, P. \& Sidhu, R. (1997). Subtypes of developmental dyslexia: Differences in phonological and orthographic coding. En B. A. Blachman (Ed.). Foundations of Reading Acquisition and Dyslexia. Mahwah: Lawrence Erlbaum Associates.

Temple, C.M. \& Marshall, J.C. (1983). A case study of developmental dyslexia. British Journal of Psychology, 74, 517-533.

Wimmer, H. (1993). Characteristic of developmental dyslexia in a regular writing system. Applied Psycholinguistics, 14, 1-33.
Wimmer, H. (1996). The early manifestation of developmental dyslexia: Evidence from German children. Reading \& Writing, 8, 171-188

Wimmer, H. \& Goswami, U. (1994). The influence of orthographic consistency on reading development: Word recognition in English and German children. Cognition, 51, 91-103.

Wimmer, H., Mayringer, H. \& Landerl, K. (1998). Poor reading: A deficit in skill- automatisation or a phonological deficit? Scientific Studies of Reading, 2, 321-340.

Wolf, M. \& Bowers, P.G. (2000). Naming speed and developmental reading disabilities. An introduction to the Special Issue on the Double-Deficit Hypothesis. Journal of Learning Disabilities, 33 (4), 322-324. 